carbonyl group, leaving it highly susceptible to nucleophilic attack. With suitable substituents $X$ and $Y$ (obviously $X=Y=\mathrm{NH} R$ cannot be generally useful), many uses for such mixed anhydrides present themselves. Reports on the systematic variation of $X$ and $Y$, together with applications of the compounds produced, will be presented shortly.

$N$-Butylphenylacetamide. Phenylacetic acid $(0.51 \mathrm{~g})$ in dry benzene $(6 \mathrm{ml}$.) was added to trisbutylaminoborane $(1 \cdot 4 \mathrm{~g})$ and the solution heated under reflux for $4 \mathrm{~h}$. The reaction mixture was diluted with ether $(5 \mathrm{ml}$.) and extracted with $3 \mathrm{~N}$ hydrochloric acid $(2 \times 5 \mathrm{ml}$.), water $(5 \mathrm{ml}$.), saturated aqueous potassium carbonate $(2 \times 5$ ml.) and water $(2 \times 5 \mathrm{ml}$.). The acid extract was brought

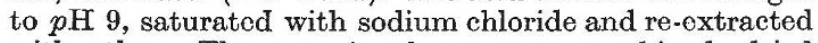
with ether. The organic phases were combined, dried with magnesium sulphate, filtered and the solvent removed to yield $0.65 \mathrm{~g}$ (90 per cent) of a pure product with a melting point of $54^{\circ}-55^{\circ} \mathrm{C}$ and which was identical in all ways with an authentic sample.

N-Butylisopropylidene imine. Diethyl ketone $(0.518 \mathrm{~g})$, trisbutylaminoborane $(1.5 \mathrm{~g})$ and benzene $(10 \mathrm{ml}$.) were heated under reflux for $8 \mathrm{~h}$. The benzene was removed at water-pump vacuum, and the remaining solution brought over at $0.1 \mathrm{~mm}$ into a cooled $\left(-75^{\circ} \mathrm{C}\right)$ receiver. Fractionation gave $0.554 \mathrm{~g}(77.5$ per cent) of a product with a boiling point of $86^{\circ} / 42 \mathrm{~mm}$; its molecular weight was $141 \cdot 1515$ (and that required for $\mathrm{C}_{8} \mathrm{H}_{19} \mathrm{~N}$ is $141 \cdot 1517$ ).

One of us (T. L.) thanks the Science Research Council for a research grant.

\section{T. LEVITT}

Andrew Pelter

Department of Chemistry,

University of Manchester.

${ }^{1}$ Nelson, P., and Pelter, A., J. Chem. Soc., 5142 (1965).

\section{Effect of Hydrogen-containing Impurities on lonization Times in Shock-heated Argon}

THE mechanism by which impurities influence the time for shock-treated argon to reach equilibrium ionization has been considered on numerous occasions ${ }^{1-4}$. No results have as yot been published, however, describing the effect of specific impurities. To remedy this situation, I am now making measurements of the total ionization times (see Fig. 1) in primary shocks through argon to which controlled amounts of various gaseous impurities have been added. The degree of ionization is monitored by following the time dependence of the intensity of the continuum emission at $4900 \AA$. Preliminary results show that hydrogen, at concentrations greater than 100 p.p.m., produces a very pronounced decrease in the total ionization time, and this communication suggests a novel explanation for this effect.

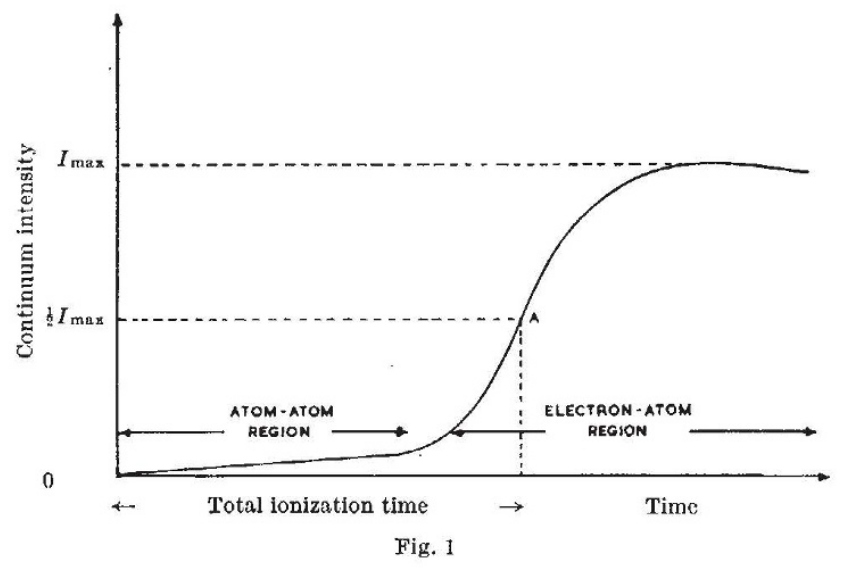

Previously it has been assumed that the sole effect of an impurity $I$ is to increase the rather slow ionization rate in the atom-atom region by a catalytic mechanism:

$$
\begin{gathered}
I+\mathrm{Ar} \rightarrow I^{*}+\mathrm{Ar} \\
I^{*}+\mathrm{Ar} \rightarrow I^{+}+\varepsilon^{-}+\mathrm{Ar} \\
I^{+}+\mathrm{Ar} \rightleftharpoons I+\mathrm{Ar}^{+}
\end{gathered}
$$

While hydrogen can participate in such a scheme, it seems unlikely that the overall rate of ionization would be increased to an extent large enough to explain the observed results.

In the electron-atom region, the rate of ionization is limited by the rate at which energy can be transferred from the translationally hot argon atoms and ions to the electrons, which lose a considerable amount of energy in the ionization process:

$$
\begin{aligned}
\mathrm{Ar} & +\varepsilon^{-} \rightarrow \mathrm{Ar}^{*}+\varepsilon^{-} \\
\mathrm{Ar} & +\varepsilon^{-} \rightarrow \mathrm{Ar}^{+}+2 \varepsilon^{-}
\end{aligned}
$$

The dominant term in the rate of energy transfer at temperatures about $10,000^{\circ} \mathrm{K}$ is that between the electrons and argon ions, and can be written:

$$
Q_{\mathrm{Ar}^{+}}=\frac{N_{\mathrm{Ar}^{+}} N_{e} e^{4}}{m_{\mathrm{Ar}^{+}}}\left(\frac{8 \pi m_{e}}{k T_{e}}\right)^{\frac{1}{2}}\left(\frac{T_{\mathrm{Ar}^{+}}}{T_{e}}-1\right) \ln \left[\frac{9\left(k T_{e}\right)^{3}}{8 \pi N_{e} e^{6}}\right]
$$

where $m_{e}, N_{e}$ and $T_{e}$ are the electron mass, number density and temperature respectively, and $m_{\mathrm{Ar}}+$ and $T_{\mathrm{Ar}}+$ can be taken equal to the corresponding atomic values. Because the hydrogen ion $\mathrm{H}^{+}$is about forty times lighter than the argon ion, this term will be increased in the presence of hydrogen to:

$$
Q_{L}=\left(1+\frac{N_{\mathrm{H}^{+}} m_{\mathrm{Ar}}}{N_{\mathrm{Ar}}+m_{\mathrm{H}^{+}}}\right) Q_{\mathrm{Ar}^{+}}
$$

At $10,000^{\circ} \mathrm{K}$, the mechanism changes ${ }^{1}$ from atom-atom to electron-atom at a degree of ionization, $\alpha$, of about $5 \times 10^{-4}$. The presence of one part in $10^{5}$ of $\mathrm{H}^{+}$will not only nearly double the rate of ionization at this point, but will extend the range over which the electron-atom mechanism is dominant to a lower value of $\alpha$. It should also be pointed out that, while the commonest hydrogencontaining impurities in a shock tube are molecular hydrogen and water, molecules with many atoms of hydrogen, for example pump oil, may well play an important part, especially since their presence may not be detected.

At concentrations above 5 parts in $10^{4}$, this effect can lead, in addition to a considerable reduction in the ionization time, to an increase in the ionization rate over the whole range of $\alpha$ for which the electron-atom mechanism is dominant, and this has been observed as an increase in the gradient of the light output with time in the electronatom region, for example, at point $A$ in Fig. 1.

I thank Prof. A. G. Gaydon for his encouragement and interest in this work.

Department of Chemical Engineering,

$$
\text { P. B. Coates }
$$

Imperial College of Science and Technology,

London, S.W.7.

'Petschek, H., and Byron, S., Ann. Phys.,1, 270 (1957).

${ }^{2}$ Harwell, K. E., and Jahn, R. G., Phys. Fluids, 7, 214 (1964); 7, 1554 (1964).

${ }^{3}$ Morgan, E. J., and Morrison, R. D., Phys. Fluids, 8, 1608 (1965).

4 Jones, N. R., and McChesney, M., Nature, 209, 1080 (1966).

\section{RADIOBIOLOGY}

\section{Effect of Total Dose, Dose Rate and Time of} Irradiation on Synthesis of Deoxyribonucleic Acid

Ir has been postulated that the process of DNA synthesis is radio-resistant. During the period of DNA synthesis of the cell cycle in regenerating rat liver, a large dose of radiation is required to produce any measurable effect ${ }^{1-3}$. This preliminary note reports three observations made from an in vivo investigation of the effect of $\mathrm{X}$-irradiation 